\title{
Decrease Level of Candida Albicans In Children With The Practice of "Pure Honey" Oral Hygiene
}

\author{
Dera Alfiyanti ${ }^{1}$, Titi Nur Hidayanti ${ }^{2}$
}

1,2 Universitas Muhammadiyah Semarang

\section{Article Info}

\section{Article History:}

Accepted Jan 15th 2018

Key words:

Oral hygiene

Pure honey $30 \%$

Candida albicans

\section{PENDAHULUAN}

Kesehatan oral perlu dijaga dalam kondisi sehat maupun dalam kondisi sakit, karena pada kondisi sakit pada flora orofaringeal dari yang lebih dominan gram positif berubah menjadi gram negatif, sehingga dapat menyebabkan terjadinya pneumonia pada anak. Angka kejadian masalah kesehatan mulut di Indonesia sudah cukup tinggi. Berdasarkan Riset Kesehatan Dasar Nasional (Riskesdas) tahun 2013, prevalensi nasional masalah kesehatan gigi dan mulut di Indonesia sebesar 25,9\% (Riskesdas, 2008). Perawatan oral higiene yang tidak adekuat pada anak yang sedang malakukan perawatan di Rumah Sakit bisa menyebabkan peningkatan infeksi nosokomial pada anak dan kolonisasi bakteri di orofaring anak, serta bisa menjadi penyebab terjadinya pneumonia (Johnstone, Spence, \& K oziol-M cLain, 2010). Kurangnya menjaga kebersihan mulut dapat menyebabkan berbagai penyakit, salah satunya yaitu candidiasis yang sering terjadi pada anak. Candida

Corresponding author:

Dera Alfiyanti

deraituaku@yahoo.com

Media Keperawatan Indonesia, Vol 1 No 1, February 2018

e-ISSN: 2615-1669

DOI:10.26714/mki.1.1.2018.35-41 
merupakan ragi komensial pada permukaan mukosa yang paling sehat, tetapi menjadi ortunistik dalam kondisi yang memungkinkan untuk memperburuk jaringan epitel, sehingga dapat mengancam jiwa (Pfaller \& Diekema, 2007). Candidiasis sering terjadi pada anak selama hospitalisasi. (Jawetz \& Adelberg, 2008; Agarwal et al., 2008). Salah satu cara untuk mempertahankan kesehatan mulut dari bakteri Candida Albicans ini yaitu perawatan oral higiene.

Oral higiene sangat penting bagi manusia, karena mulut merupakan pintu utama masuknya bakteri ke dalam tubuh, bisa melalui makanan dan minuman (Sariningsih, 2012). Salah satu tujuan oral hygiene pada pasien anak yang dirawat di Rumah Sakit adalah untuk mencegah komplikasi dari kebersihan mulut yang kurang baik di Rumah Sakit, mengurangi plak gigi dan dekontaminasi orofaring, mengurangi risiko infeksi (seperti ventilator associated pneumonia/ VAP), mencegah kerusakan gigi dan penyakit gusi, meningkatkan kenyamanan pasien baik jangka pendek maupun jangka panjang, membantu memperkuat perkembangan gigi, dan menjaga perawatan mulut yang konsisten dan teratur di ruang perawatan anak (Johnstone, Spence, \& Koziol-M cLain, 2010). Menurut penelitian ada beberapa cairan yang dapat digunakan untuk perawatan oral hygiene diantaranya cairan $\mathrm{NaCl}$, povidone iodin $1 \%$, chlorhexidine $0,2 \%$, dan madu murni. Dalam penelitian lain menyatakan bahwa penggunaan bahan kimia saat melakukan perawatan oral higiene kurang efektif dan memiliki efek samping yang kurang sehat untuk pasien terutama apabila di terapkan pada anakanak. Menurut Potting et al (2006) juga menyatakan chlorhexidine menyebabkan iritasi, perubahan flora normal rongga mulut dan iodine menyebabkan risiko hipertiroid. Oleh karena itu perawatan oral higiene sebaiknya menggunakan bahan alami yang aman untuk kesehatan, seperti madu.
Madu merupakan salah satu bahan makanan produk dari nektar bunga yang didalamnya terdapat cairan manis dan di hisap oleh lebah kemudian dikumpulkan di sarang lebah sebagai persediaan makanan untuk lebah itu sendiri (Mottalebnejad, 2008). Madu dapat digunakan sebagai perawatan oral higiene, karena madu mengandung flavanoid yang berfungsi sebagai antibakterial (Yahya, 2006). Selain antibakterial madu juga sebagai antioksidan (untuk penangkal racun), antitumor, anti inflamasi dan antiviral (Kucuk et al, 2007). Madu juga mengandung mineral yang tinggi, mineral inilah yang dapat mengubah pH saliva yang semula asam menjadi basa pada mukosa mulut, sehingga kesehatan mulut bisa terjaga (Purbaya, 2007).

Madu memiliki kandungan air yang rendah, madu juga memiliki kandungan enzim glukosa oksidase (mengkonversi glukosa menjadi glucose acid), memiliki osmolaritas tinggi (berfungsi mengekstrak air dari sel bakteri), kandungan asam dalam madu rendah (pH:3,3-4,7) dan mengandung hydrogen peroksida) (Banaeian et al, 2013). Hydrogen peroksida memiliki manfaat untuk membunuh mikroba seperti staphylococcus aureus, micrococcus luteus, streptococcus aureus, bakteri gram positif dan bakteri gram negatif (Bogdanov 2011). Menurut Bogdanov (2009) madu terdiri dari air (17\%), fruktosa $(38,2 \%)$, glukosa $(31,3 \%)$, sukrosa $(0,7 \%)$, disakarida lainnya $(5 \%)$, erlose $(0,8 \%)$, oligosakarida lainnya $(3,6 \%)$, melezitose $(<0,1 \%)$, mineral $(0,2 \%)$, asam amino $(0,3 \%)$, asam $(0,5 \%)$ dan $\mathrm{pH}$ sekitar 3,3 - 3,9. Hidrogen peroksida juga dapat mengaktivasi protease untuk meningkatkan aliran darah perkutan pada jaringan iskemik sehingga menstimulasi pembentukan jaringan baru yang akan membentuk radikal bebas sehingga dapat mengaktivasi respon antiinflamasi (Evans \& Flavins, 2008).

Banyak penelitian yang menyatakan manfaat madu sebagai antifungi (anti jamur). Kebanyakan jenis madu menghasilkan hidrogen peroksida ketika 
diencerkan karena aktivitas enzim glukosa, yang mengoksidadi glukosa untuk glukonat asam dan hidrogen peroksida. Penelitian Maria dan Silvia (2011), menyatakan bahwa madu lavender mengandung berbagai konsentrasi, dimana komponen tersebut berfungsi sebagai antifungi (anti jamur) melalui uji in vitro terhadap Candida albicans, Candida krusei, dan Cryptococcus neoformans. Madu memiliki kandungan zat anti oksidan yang terdiri dari flavonoid, polyphenol, phenol, dan volatin. Jumlah dari kandungan anti oksidan tersebut berkisar 2 - $46 \mathrm{mg} / \mathrm{kg}$. Ektrak flavonoid pada madu dapat membantu mengobati infeksi jamur dan menunjukkan anti-candida (Candiracci, dkk, 2011). Madu juga mengandung sejumlah mikroorganisme (yeast), diantaranya Aspergillum dan Penicillium yang dapat berfungsi sebagai anti fungal (Persano et al, 2008 dalam Borganov, 2009). Mengingat infeksi jamur yang sangat besar di lingkungan masyarakat maupun di lingkungan rumah sakit. Diantara Candidiasis ini, Candida Krusei yang merupakan patogen oportunistik yang dapat menyebabkan infeksi serius pada pasien yang rentan (Nguyen et al. 2010).

\section{METODE}

Penelitian ini menggunakan metode kuasi eksperimen pre dan post desain dengan kelompok kontrol. Populasi penelitian ini adalah semua anak yang menjalani hospitalisasi. Sampel diambil dengan tehnik purposive sampling, sejumlah 20 anak (10 anak kelompok kontrol, 10 anak kelompok intervensi). Metode yang digunakan untuk menghitung jamur yaitu metode Plate Count.
HASIL

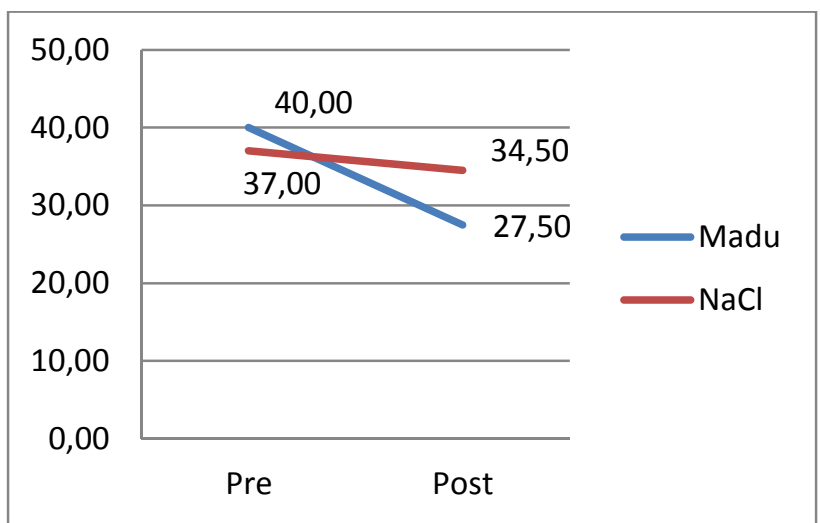

Grafik 1. Jumlah Jamur Candida Sebelum Diberikan Oral Higiene dengan Madu 30\% dan $\mathrm{NaCl}$ di Ruang Ismail RS Roemani Semarang

Berdasarkan grafik tersebut, diperoleh distribusi jumlah jamur candida albicans di mulut pre test madu sebesar $40.00 \mathrm{CFU} / \mathrm{ml}$ dengan standar deviasi $\pm 6.855 \mathrm{CFU} / \mathrm{ml}$. Rerata jumlah jamur candida albicans di mulut pre test $\mathrm{NaCl}$ sebesar $27.00 \mathrm{CFU} / \mathrm{ml}$ dengan standar deviasi $\pm 11.424 \mathrm{CFU} / \mathrm{ml}$. Rerata jumlah jamur candida albicans di mulut post test madu murni 30\% sebesar $27.50 \mathrm{CFU} / \mathrm{ml}$ dengan standar deviasi $\pm 2.633 \mathrm{CFU} / \mathrm{ml}$. Jumlah jamur candida albicans post test $\mathrm{NaCl}$ sebesar 34.50 $\mathrm{CFU} / \mathrm{ml}$ dengan standar deviasi \pm 7.321 $\mathrm{CFU} / \mathrm{ml}$.

Tabel 1. Perbedaan Jumlah Jamur Candida Albicans Sesudah Diberikan Oral Higiene dengan Madu Murni 30\% di Ruang Ismail

RS Roemani Semarang, N=20

\begin{tabular}{|l|c|c|c|}
\hline \multicolumn{1}{|c|}{ Indikator } & $\begin{array}{c}\text { Kelompok } \\
\text { intervensi }\end{array}$ & $\begin{array}{c}\text { Kelompok } \\
\text { kontrol }\end{array}$ & $\begin{array}{c}\mathrm{p}- \\
\text { value }\end{array}$ \\
\hline $\begin{array}{l}\text { Rerata jumlah } \\
\text { Candida Albicans } \\
\text { sebelum } \\
\text { intervensi }\end{array}$ & $\begin{array}{c}27,40 \\
( \pm 2,633)\end{array}$ & $\begin{array}{c}39,50 \\
( \pm 11,424)\end{array}$ & 0,888 \\
\hline $\begin{array}{l}\text { Rerata jumlah } \\
\text { Candida Albicans } \\
\text { setelah } \\
\text { intervensi }\end{array}$ & $\begin{array}{c}27,40 \\
( \pm 2,633)\end{array}$ & $\begin{array}{c}39,50 \\
( \pm 11,424)\end{array}$ & 0,004 \\
\hline $\begin{array}{l}\text { Perubahan } \\
\text { jumlah Candida }\end{array}$ & $-115,000$ \\
$\begin{array}{l}\text { Albicans } \\
\text { sebelum dan } \\
\text { setelah } \\
\text { intervensi }\end{array}$ & $( \pm 677,003)$ & $\begin{array}{c}0,0000 \\
( \pm 0,000)\end{array}$ & 0,000 \\
\hline
\end{tabular}


Berdasarkan uji statistik dengan menggunakan uji dependent T-test didapatkan hasil jumlah jamur candida pre test madu murni sebesar $38.90 \mathrm{CFU} / \mathrm{ml}$ dengan standar deviasi $\pm 6.168 \mathrm{CFU} / \mathrm{ml}$ dan untuk hasil pre test $\mathrm{NaCl}$ sebesar 39.50 $\mathrm{CFU} / \mathrm{ml}$ dengan standar deviasi \pm 3.612 $\mathrm{CFU} / \mathrm{ml}, p$ value sebesar 0,888 ( $p$ value $\geq$ $0,05)$ maka belum ada pengaruh pada jumlah jamur candida pre test madu dan $\mathrm{NaCl}$. Berdasarkan analisis statistik dengan menggunakan uji Independent t-test didapatkan rata-rata jumlah jamur candida albicans pada post test madu $27.40 \mathrm{CFU} / \mathrm{ml}$ dengan standar deviasi $\pm 2.633 \mathrm{CFU} / \mathrm{ml}$, sedangkan rata-rata jumlah candida albicans pada post test $\mathrm{NaCl} 39.50 \mathrm{CFU} / \mathrm{ml}$ dengan standar deviasi $\pm 11.424 \mathrm{CFU} / \mathrm{ml}$. Hasil $p$-value 0.004 dimana ( $p$ value $\leq 0.05$ ), maka ada pengaruh penggunaan madu murni dalam oral higiene terhadap jumlah jamur candida albicans di dalam mulut. Data hasil delta kelompok madu sebesar $115.000 \mathrm{CFU} / \mathrm{ml}$ dengan standar deviasi $\pm 677.003 \mathrm{CFU} / \mathrm{ml}$, untuk hasil delta pada kelompok $\mathrm{NaCl}$ sebesar $0.0000 \mathrm{CFU} / \mathrm{ml}$ dengan standar deviasi \pm 0.00000 dan hasil $p$ value sebesar 0.000 ( $p$ value $\leq 0.05)$, maka dapat disimpulkan bahwa ada penurunan yang signifikan jumlah jamur candida albicans setelah diberikan madu murni 30\% dibandingkan setelah diberikan $\mathrm{NaCl}$.

\section{PEMBAHASAN}

Jumlah jamur candida albicans sebelum dilakukan Oral Higiene menggunakan madu $30 \%$ diperoleh rata-rata $38.90 \mathrm{CFU} / \mathrm{ml}$ dengan standar deviasi $6.855 \mathrm{CFU} / \mathrm{ml}$, sedangkan rata-rata jumlah jamur candida albicans post test pada kelompok kontrol $(\mathrm{NaCl})$ adalah $39.50 \mathrm{CFU} / \mathrm{ml}$ dengan standar deviasi $11.424 \mathrm{CFU} / \mathrm{ml}$. Jamur pada mulut merupakan ragi yang tumbuh di dalam rongga mulut, dan dapat berubah menjadi patogen dalam kondisi-kondisi tertentu. Perawatan oral higiene yang tidak adekuat pada anak selama hospitalisasi bisa menyebabkan peningkatan infeksi nosokomial pada anak dan kolonisasi bakteri di orofaring anak, serta bisa menjadi penyebab terjadinya pneumonia (Johnstone, Spence, \& K oziol-M cLain, 2010). Penelitian Silvia, dkk (2011), ratarata jumlah jamur candida albicans 31.0 CFU/ml. Pada penelitian Mariyam \& Alfiyanti (2014), rata-rata jumlah koloni bakteri pada kelompok kontrol yaitu 36 $\mathrm{CFU} / \mathrm{ml}$ dengan standar deviasi 92.87 $\mathrm{CFU} / \mathrm{ml}$.

Hasil rata-rata jumlah jamur candida dalam penelitian ini pada post test yaitu 27.40 $\mathrm{CFU} / \mathrm{ml}$ dengan standar deviasi 2.633 CFU/ml, sedangkan rata-rata jumlah jamur candida albicans post test pada kelompok kontrol $(\mathrm{NaCl})$ adalah $39.50 \mathrm{CFU} / \mathrm{ml}$ dengan standar deviasi $11.424 \mathrm{CFU} / \mathrm{ml}$. Pada penelitian Moussa, dkk (2009) menyatakan bahwa berkumur dengan madu murni dengan konsentrasi 30\% - 50\% dapat menghambat pertumbuhan beberapa mikroorganisme patogen, termasuk Candida Albican. Menurut Estevinho (2008) menyatakan kandungan asam fenolik, favonoid dan molekul lainnya yang ada di dalam madu dipercaya dapat menghambat pertumbuhan jamur. Penelitian Mariyam \& Alfiyanti (2014), rata-rata jumlah koloni bakteri pada kelompok intervensi post test adalah 4.2 dengan standar deviasi 3.42 CFU/ml. Penelitian Silvia, dkk (2011), ratarata jumlah jamur candida albicans kelompok intervensi post test adalah 29.4 $\mathrm{CFU} / \mathrm{ml}$.

Uji normalitas yang digunakan pada penelitian ini adalah Uji Saphiro-Wilk pada variabel yang berskala numerik. Hasil ini sejalan dengan penelitian Candiracci dkk, (2011) menunjukkan bahwa ekstrak flavonoid madu mampu menghambat pertumbuhan Candida albicans. Penelitian ini dilakukan bertujuan untuk melihat pengaruh penggunaan madu murni dalam oral higiene terhadap jumlah candida albicans pada mulut anak selama hospitalisasi. Jamur pada mulut merupakan ragi yang tumbuh di dalam rongga mulut, dan dapat berubah menjadi patogen dalam kondisi-kondisi tertentu. Perawatan oral 
higiene yang tidak adekuat pada anak selama hospitalisasi bisa menyebabkan peningkatan infeksi nosokomial pada anak dan kolonisasi bakteri di orofaring anak, serta bisa menjadi penyebab terjadinya pneumonia (Johnstone, Spence, \& K oziol-M cLain, 2010).

Penelitian ini menyatakan adanya pengurangan jumlah jamur candida sebelum dan sesudah dilakukan oral higiene dengan madu murni 30\% dan dari hasil uji analisis statistik pada kedua kelompok pre test madu maupun $\mathrm{NaCl}$ didapatkan hasil $\mathrm{p}$ value 0.888 . Hal ini menunjukkan bahwa tidak ada pengaruh atau perbedaan yang signifikan antara kelompok intervensi maupun kelompok kontrol. Hasil uji independent $\mathrm{T}$ Test pada kelompok post test madu dan $\mathrm{NaCl}$ didapatkan hasil yang signifikan, hasilnya adalah $\mathrm{p}$ value $=0,004$ ( $\mathrm{p}$ value $\leq 0,05$ ). Maka ada perbedaan yang signifikan antara jumlah candida albicans di mulut anak selama hospitalisasi sebelum dan sesudah dilakukan oral higiene dengan madu murni $30 \%$.

Berdasarkan penelitian ini jumlah jamur candida setelah dilakukan oral higiene dengan madu murni $30 \%$ mengalami pengurangan rata-rata $27.40 \mathrm{CFU} / \mathrm{ml}$. Sedangkan hasil rata-rata untuk kelompok kontrol $(\mathrm{NaCl})$ post test didapatkan 39.50 $\mathrm{CFU} / \mathrm{ml}$. Menurut penelitian Candiracci dkk, (2011) menunjukkan bahwa ekstrak flavonoid madu mampu menghambat pertumbuhan Candida albicans. Menurut penelitian Candiracci dkk, (2011) menunjukkan bahwa ekstrak flavonoid madu mampu menghambat pertumbuhan Candida albican. Penelitian ini menyatakan adanya perbedaan pengurangan jumlah jamur candida sebelum dan sesudah dilakukan oral higiene dengan madu murni $30 \%$ dan $\mathrm{NaCl}$. Hasil rerata jamur candida dari pre test madu $30 \%$ sebesar 38.90 $\mathrm{CFU} / \mathrm{ml}$ dengan standar deviasi 6.855 $\mathrm{CFU} / \mathrm{ml}$ dan untuk rerata jumlah jamur candida post test madu sebesar 27.40 $\mathrm{CFU} / \mathrm{ml}$ dengan standar deviasi 2.633 $\mathrm{CFU} / \mathrm{ml}$. Sedangkan untuk rata-rata jumlah jamur candida albicans pada pre test $\mathrm{NaCl}$ sebesar $39.50 \mathrm{CFU} / \mathrm{ml}$ dengan standar deviasi $11.424 \mathrm{CFU} / \mathrm{ml}$, dan untuk rerata hasil jamur candida post test $\mathrm{NaCl}$ sebesar $36.40 \mathrm{CFU} / \mathrm{ml}$ dengan standar deviasi 7.321 $\mathrm{CFU} / \mathrm{ml}$. Dari hasil tersebut dapat disimpulkan bahwa $\mathrm{p}$ value $\leq 0.05$ yaitu $\mathrm{p}$ value $0.004 \mathrm{CFU} / \mathrm{ml}$, dimana ada pengaruh yang signifikan antara jumlah jamur candida post test madu dengan jumlah jamur candida post test $\mathrm{NaCl}$. Jumlah jamur post test madu lebih sedikit dibandingkan jumlah jamur candida post test $\mathrm{NaCl}$. Hasil ini sejalan dengan hasil penelitian dari Moussa, dkk (2009) menyatakan bahwa berkumur dengan madu murni dengan konsentrasi $30 \%$ - 50\% dapat menghambat pertumbuhan beberapa mikroorganisme patogen, termasuk Candida Albican.

Hasil Penelitian Mariyam \& Alfiyanti (2014), rata-rata jumlah koloni bakteri pada kelompok intervensi post test adalah 4.2 dengan standar deviasi $\pm 3.42 \mathrm{CFU} / \mathrm{ml}$. Adanya perbedaan jumlah jamur antara kelompok madu dengan kelompok $\mathrm{NaCl}$ dikaitkan dengan kandungan madu yang berfungsi sebagai antifungi. Penelitian Bogdanov (2011) menyatakan bahwa hidrogen peroksida efektif membunuh mikroba seperti staphylococcus aureus, micrococcus luteus, streptococcus aureus, bakteri gram positif dan bakteri gram negatif.

\section{SIMPULAN}

Jumlah jamur candida albicans pada anak sebelum dilakukan oral higiene dengan madu murni $30 \%$ adalah $38.90 \mathrm{CFU} / \mathrm{ml}$ dengan standar deviasi $\pm 6.855 \mathrm{CFU} / \mathrm{ml}$. Jumlah jamur candida albicans pada anak sesudah dilakukan oral higiene dengan madu murni $30 \%$ adalah $27.40 \mathrm{CFU} / \mathrm{ml}$ dengan standar deviasi $\pm 2.633 \mathrm{CFU} / \mathrm{ml}$. Hasil uji statistik p value sebesar 0,001 (p value $\leq 0,05$ ) menunjukkan bahwa ada perbedaan yang signifikan antara jumlah jamur candida sebelum dan sesudah dilakukan oral higiene menggunakan madu 
$30 \%$ pada anak selama hospitalisasi di Ruang Ismail 2 RS Roemani Semarang.

\section{REFERENSI}

Alnaimat, S., Wainwright, M ., Al Abri, K . (2012). Antibacterial potential of honey from different origins: a comparison with manuka honey. Journal of M icrobiology, Biotechnology and Food Sciences 2012: 1(5):1328-1338

Moussa, A, D. N. (2012). Additive potential of ginger starch on antifungal potency of honey against Candida albicans. Asian Pac J Trop Biomed.

Moussa, Noureddine, Saad, Abdelmelek \& Abdelkader. (2009). Antifungial activity of four honeys of different types from Algeria againts pathogenic yeast : Candida albicans and Rhodotorula s. Asian Pacific Journal of Tropical Biomedicine

Bogdanov. (2011). Honey as a nutrient and fuctional food. Bee Product Science, 3 (2), 1-3. .

Candiracci M, C. B. (2012 ; 131 (2) : 493 - 499). Antifungal activity of the honey flavonoid extract against Candida albicans. Food Chem.

Candiracci, M. C. (2011). Honey flavonoids, natural antifungal agents against Candida albicans.International Journal of Food Properties, 14(4), 799-808.

Daniluk T, 0. T. (2006 ; 51 (3) : 77-81). Occurrence rate of oral Candida albicans in denture wearer patient. Adv med sci.

Estevinho L, P. A. (2008). Antioxidant and antimicrobial effects of phenolic compound extracts of Northeast Portugal honey. Food Chem Toxicol.

Evans, J. \&. (2008). Honey: a guide for healthcare professionals.British Journal of Nursing, 17(15),24-30. India: Association of Food Scientist \& Technologist.

Evans, J. \&. (2008). Honey: a guide for healthcare professionals.British Journal of Nursing, 17(15),24-30.

Ihsan, A. (2011). Khasiat dan Manfaat Madu Herbal. jakarta: Agro Media Pustaka.

Jawetz, M. (2008). Mikrobiologi Kedokteran Edisi 23. Jakarta: Buku Kedokteran.
Kaziol, M. D. (2010). Oral Higiene Care In The Pediatric Recommendation. Pediatric Nursing.

Kesehatan, K. (2010). Profil Kesehatan Indonesia 2009. Jakarta: Depkes.

Kucuk, M., Kolayl, S., Karaoglu, S., Ulusoy, E., Baltac, C., \& Candan, F. (2007). Biological activities and chemical composition of three honeys of different types from Anatolia. Food Chem, $100 ; 526-534$.

Maria LE, A. S. (2011; 48 (5);640-643). Antifungal effect of lavender honey against Candida albicans, Candida krusei and Cryptococcus neoformans. J Food Sci Technol.

Maryam \& Alfiyanti, D. (2014). Koloni bakteri pada anak yang dirawat di PICU setelah oral hygiene dengan Nacl.

Nguyen. (2010). Characterising the post-antifungal effects of micafun-gin against Candida albicans, Candida glabrata, Candida parapsilosis and Candida kruseiisolates. Int J Antimicrob Agents 35:80-84.

Notoatmodjo, S. (2012). Metodologi Penelitian Kesehatan. Jakarta: Rineka Cipta.

Pfaller, M. D. (2007). Epidemiology of invasive candidiasis: a persistent public health problem.Clinical Microbiology Reviews. 20,133-163.

Pithon, M. a. (2015). Assesment Of The Effectiveness Of Mouthwashes In Reducing Cariogenic Biofilm In Ortodentic Patients : A Systematic Review. Journal Of Dentistry.

Potting, C. R. (2006). The effectiveness of commonly used mouthwashes for the prevention of chemotherapy-induced oral mucositis: A systematic review. European Journal of Cancer Care, 15 (1), 431-439.

Purbaya, J. (2007). Mengenal dan Memanfaatkan Khasiat Madu Alami. Bandung: Pinonir Jaya.

RI, B. P. (2007). Laporan Hasil Riset Kesehatan Dasar (RISKESDAS) Nasional.

Sabirin, I. P. (2015). Sitologi Eksfoliatif Mukosa Oral sebagai Pemeriksaan Penunjang di Koedokteran Gigi. Jurnal Kedokteran dan Kesehatan, Vol. 2, No. 1.

Sariningsih, E. (2012). Merawat Gigi Anak Sejak Usia Dini. Jakarta : Gramedia. 
Supartini, Y. (2014). Konsep Dasar Keperawatan Anak. Jakarta: EGC.

Patton T, Barrett J, Brennan J, Moran N. Use of a spectrophotometric bioassay for determination of microbial sensitivity to manuka honey. J Microbiol Methods 2006 ; 64 : 84-95

Supranto, J. (2007). Teknik Sampling untuk Survei dan Eksperimen Edisi 4. Jakarta : Rineka Cipta. 